\section{THE GOLD STANDARD FOR THE BULK FILL TECHNIQUE}

To celebrate the five year anniversary of Smart Dentine Replacement (SDR), DENTSPLY is offering new and existing customers some very special SDR anniversary deals.

Since its introduction to the market five years ago SDR has become the bulk-fill composite base material of choice for dental professionals. Easy, quick and predictable SDR exhibits outstanding adhesion to dentine in all cavity geometries whilst remaining adaptive to hard tissue. Its flowability and self-levelling properties reduce the occurrence of voids and bubbles which lessen the possibility of post-operative sensitivity.

SDR can be used in daily practice for a range of clinical needs, including the base of Class I and II direct restorations, as a liner under direct restorative materials, pit and fissure sealant, and as an effective and efficient core build-up material.

For a demonstration and FREE sample of SDR or to purchase DENTSPLY's special five year anniversary SDR kit containing 110 compulas and two limited edition golden storage boxes with 18\% discount, contact DENTSPLY on 08000723313 or visit dentsply.co.uk.

\section{THE INJECTABLE COMPOSITE} FOR ALL INDICATIONS

G-aenial Universal Flo is GC's unique and highly wearresistant injectable composite for general restorative use including all Class I to V cavities.

With the physical performance of a regular composite, it is highly thixotropic and stays in place, holding its shape for ease of use. Users find it to be virtually self-polishing with superb aesthetics. Its indications are for direct restorations, minimum intervention cavities and fissure sealing.

Incorporating innovative filler technology, it features a high filler load and a homogeneous dispersion of fillers, resulting in high strength and great wear resistance. Studies have confirmed that it has higher strength, higher wear resistance and higher gloss retention than other tested flowable composites; it even rivals leading conventional composites in these categories.

G-aenial Universal Flo is dispensed through an ergonomically designed syringe that enables smooth delivery of the material, with a tapered tip that means no paste sticks to it. The design also prevents waste because minimal residual paste remains in the syringe after use.

For further information contact GC UK Ltd on 01908218999.

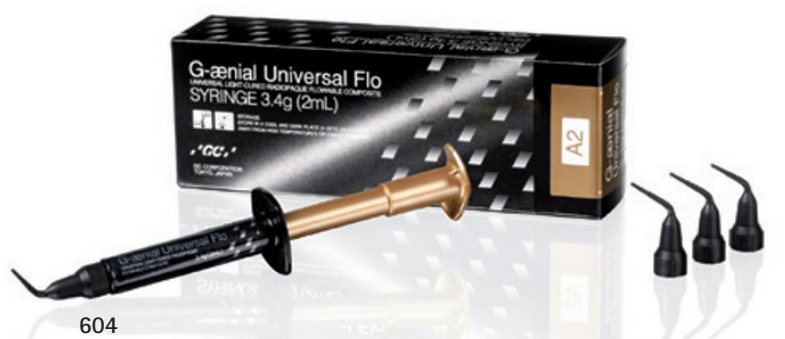

\title{
BRIDGING THE GAP BETWEEN PROFESSIONAL AND HOME CARE
}

In aesthetic dentistry, preventive maintenance is one of the keys to increasing the success rate of cosmetic treatments and decreasing risks of failure due to poor oral hygiene.

Developed, used and recommended by dental care professionals the UltraDEX Performance Oral Care range fits perfectly within the process of dental care, before, during and after treatment. With excellent performance in eliminating both volatile sulphur compounds and oral bacteria, UltraDEX helps to prevent plaque biofilm, protecting both teeth and gums. Patient compliance is excellent. UltraDEX

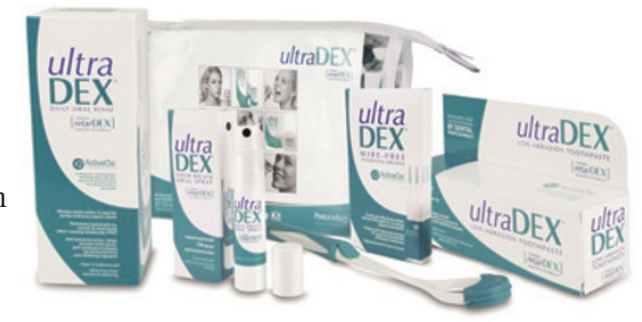
daily use and has the additional benefit of gently oxidising organic stains. Free from alcohol and sodium lauryl sulphate, UltraDEX bridges the gap between professional and home care and is backed by scientific research. For further information, please visit our website www.periproducts.co.uk or email dental@periproducts.co.uk. is safe and effective for long-term

\section{DUE DILIGENCE FOR DENTAL PRACTICES}

If you are thinking of acquiring a dental practice, make sure that detailed due diligence is undertaken prior to any legal commitment.

As professional dental lawyers, Goodman Grant will carry out due diligence on both the property and the practice. This begins with property searches and Commercial Property Standard Enquires (CPSE) specific to a dental practice.

Goodman Grant then continues with enquiries into every detail and area of running a practice. This covers compiling an inventory of the equipment with copies of regulatory certificates and documentation, CQC regulations and compliance, NHS contracts and UDA performance statistics.

Due diligence is crucial to ensure that you do not inherit problems and to protect yourself from a plethora of legal complication. Contact Goodman Grant on 01138343705 or email jmg@goodmangrant.co.uk.

\section{DEVELOP YOUR PROFITABILITY}

Business IQ is a new initiative developed to positively impact the profitability of dental practices.

Bringing together the core service offerings from Software of Excellence and Henry Schein Dental, along with expertise from a range of third party partners, Business IQ aims to improve your business performance through a range of practical solutions, under the headings: Consult, Learn, Grow.

Consult: Finding a trusted advisor for your business can be difficult. Whether you want to benefit from the business tools within EXACT from Software of Excellence, to explore the latest digital restorative solutions or are thinking about refurbishing your practice, Business IQ has a solution to help.

Learn: Ensure your team are up to date with training and Core CPD. Through Business IQ you'll be able to choose from a wide range of clinical and non-clinical courses that will help to improve both practice and personal development.

Grow: From reduced rates on recruitment and financial advice, through to all aspects of practice marketing, including patient literature and developing patient engagement through social media, Business IQ has a range of solutions to help your practice grow.

To see how Business IQ can help your business call 08000232558 or visit www.hsbusinessiq.co.uk. 